\title{
Frecuencia de contaminación por enteroparásitos en pasamanos de autobuses de Barquisimeto, Venezuela
}

Enteric Parasite Contamination Frequency on Bus Handrails in Barquisimeto, Venezuela

Frequência da contaminação por enteroparasitos em corrimãos de ônibus em Barquisimeto, Venezuela

Luis Eduardo Traviezo Valles, Lcdo., MSc., Prof. ${ }^{1}$ (D), Camila Villamediana Moncada, Est. $^{2}$ (iD, Luis Jaimes Peña, Est. ${ }^{3}$ (iD

1. Licenciado en Bioanálisis, Maestro en Protozoología, Profesor titular de Parasitología Médica. Universidad Centroccidental "Lisandro Alvarado" (UCLA), Decanato de Ciencias de la Salud, Sección de Parasitología Médica, Barquisimeto, Venezuela.

2. Estudiante de Enfermería. Universidad Centroccidental "Lisandro Alvarado", Decanato de Ciencias de la Salud, Barquisimeto, Venezuela.

3. Estudiante del Colegio Andrés Bello. Barquisimeto, Venezuela.

Correspondencia. Luis Eduardo Traviezo Valles. Urbanización Tierra del Sol 2, Casa A-29, Cabudare, estado Lara, Venezuela. Móvil: +58 414 5244736, E-mail: luisetraviezo@hotmail.com y ltravies@ucla.edu.ve

\section{INFORMACIÓN DEL ARTÍCULO:}

Artículo recibido: 22 de mayo de 2020

Artículo aceptado: 16 de septiembre de 2020

DOI: https://doi.org/10.29375/01237047.3913

Cómo citar: Traviezo, L. Frecuencia de contaminación por enteroparásitos en pasamanos de autobuses de Barquisimeto, Venezuela. MedUNAB. 2020;23(3):434-440 doi: https://doi.org/10.29375/01237047.3913

\section{RESUMEN:}

Introducción. La contaminación enteroparasitaria en autobuses por parte de usuarios infectados con malas conductas sanitarias potencia el riesgo de infección del resto de los pasajeros con el subsecuente peligro del desarrollo de patologías 
gastrointestinales. Por esto se evaluó la frecuencia de contaminación de autobuses con el fin de aportar datos que son desconocidos en Venezuela e inexistentes en Latinoamérica. Metodología. El trabajo fue descriptivo, transversal, con muestra no probabilística y accidental, donde la obtención de la muestra consistió en frotar el pasamanos de cada autobús (100 vehículos examinados) tres veces con un hisopo impregnado en solución salina isotónica $0.85 \%$, resuspendiendolo en un tubo de ensayo con $10 \mathrm{ml}$ de solución salina. La muestra se centrifugó a 3000 rpm por diez minutos para luego observar el sedimento al microscopio. Resultados. El 16\% de las muestras presentaron contaminación, encontrándose solo dos especies de enteroparásitos, Blastocystis spp. (14\% del total de muestras examinadas) y Endolimax nana (5\%). Discusión. La abundancia del potencial patógeno Blastocystis sp., se relaciona con lo descrito en exámenes de heces de habitantes de Barquisimeto y del estado Lara, demostrando que los usuarios enfermos con malas conductas higiénicas convierten a los autobuses en un foco de infección que debe ser controlado. Conclusión. La falta de aseo constante en unidades de transporte público y la ausencia de conciencia sanitaria de algunos pasajeros infectados facilitan la transmisión de enteroparásitos endémicos potencialmente productores de enfermedades gastrointestinales.

Palabras claves:

Parásitos; Fómites; Blastocystis; Endolimax; Venezuela.

\section{ABSTRACT}

Introduction. Enteroparasite contamination by infected users with poor sanitary habits in buses increases other passengers' risk of infection, with the subsequent danger of developing gastrointestinal pathologies. For this reason, bus contamination frequency was evaluated in order to provide data that is unknown in Venezuela and non-existent in Latin America. Methodology. The work was descriptive and cross-sectional, with non-probability and accidental sampling. The sample was obtained by rubbing each bus' handrail (100 examined vehicles) three times with a swab permeated with a $0.85 \%$ isotonic saline solution, resuspending it in a test tube with $10 \mathrm{ml}$ of saline solution. The sample was centrifuged at 3,000 rpm for ten minutes to then observe the sediment under a microscope. Results. Sixteen percent of samples were contaminated, observing only two species of enteroparasites, Blastocystis sp. (14\% of total examined samples) and Endolimax nana (5\%). Discussion. The abundance of the potential pathogen, Blastocystis sp. is related to what has been described in feces exams on the inhabitants of Barquisimeto and the state of Lara, demonstrating that sick users with poor hygiene habits make buses a point of infection that must be controlled. Conclusion. The lack of constant cleaning in public transportation units and the absence of some infected passengers' sanitary awareness facilitates transmitting endemic enteroparasites that could potentially produce gastrointestinal diseases.

Keywords:

Parasites; Fomites; Blastocystis; Endolimax; Venezuela.

\section{RESUMO}

Introdução. A contaminação enteroparasitária em ônibus por usuários infectados com comportamentos sanitários inadequados aumenta o risco de infecção do resto dos passageiros com o consequente perigo de desenvolvimento de patologias gastrointestinais. Por isso, avaliouse a frequência de contaminação de ônibus, a fim de fornecer dados até agora desconhecidos na Venezuela e inexistentes na América Latina. Metodologia. O trabalho foi descritivo, transversal, com amostra não-probabilística e acidental, em que a obtenção da amostra consistiu em esfregar o corrimão de cada ônibus (100 veículos examinados) três vezes com um cotonete impregnado em solução salina isotônica $0.85 \%$, ressuspendendo-o em um tubo de ensaio com $10 \mathrm{ml}$ de solução salina. A amostra foi centrifugada a 3,000 rpm por dez minutos para posteriormente observar o sedimento ao microscópio. Resultados. $16 \%$ das amostras apresentaram contaminação, sendo encontradas apenas duas espécies de enteroparasitas, Blastocystis sp. (14\% do total das amostras examinadas) e Endolimax nana (5\%). Discussão. A abundância do potencial patógeno Blastocystis sp., está relacionada ao que foi descrito em exames de fezes de moradores dos estados 
de Barquisimeto e Lara, mostrando que usuários doentes e com comportamentos sanitários inadequados fazem do ônibus um foco de infecção que deve ser controlado. Conclusão. A falta de limpeza constante nas unidades de transporte público e a falta de conscientização sobre a saúde de alguns passageiros infectados facilitam a transmissão de enteroparasitos endêmicos potencialmente produtoras de doenças gastrointestinais.

Palavras-chave:

Parasitas; Fômites; Blastocystis; Endolimax; Venezuela

\section{Introducción}

En general, las parasitosis han producido mayor cantidad de decesos que los contabilizados en las guerras en la historia de la humanidad (1), siendo las enteroparasitosis un problema grave a nivel mundial, especialmente en Latinoamérica, en donde la prevalencia ronda entre $20 \%$ y $30 \%$ de sus habitantes. Esta estimación puede resultar muy baja si se tienen en cuenta a los portadores asintomáticos, quienes no ingresan en estos registros, ya que no acuden a las instituciones sanitarias (2-4). Se calcula que existen aproximadamente 3,500 millones de individuos infectados en el mundo, de los que apenas 450 millones manifiestan algún tipo de signo o síntoma (2).

El aumento de casos de parasitosis intestinal estáasociado a la falta de higiene; susceptibilidad del huésped, como ciertas debilidades en el sistema inmune; precarias condiciones culturales y socioeconómicas (que vienen acompañadas de deficiencias en los servicios sanitarios, falta e inadecuada calidad del agua, escasez de letrinas, etc.); o factores geográficos y climáticos junto con condiciones ecológicas propicias, como la abundancia de vectores mecánicos (moscas, cucarachas, roedores) y principalmente la contaminación fecal (1-4).

En el estado Lara, Venezuela, la prevalencia de parásitos intestinales ronda entre el $27 \%$ y el $71 \%$ de sus habitantes, detectándose un constante predominio de los protozoarios sobre los helmintos, de tal manera que el Blastocystis spp, es el principal enteroparásito observado, seguido por el comensal Endolimax nana. Es por esto que ambos taxones conforman la asociación parasitaria (especies agrupadas en el mismo individuo) más frecuente en pacientes de este estado y de otras regiones de Venezuela $(4,5)$.

La contaminación parasitaria de fómites (vector pasivo) es un punto significativo en la transmisión, donde se ha encontrado un $65 \%$ de contaminación en intercomunicadores con una variedad de diez taxones (4). También se reportó un $29 \%$ de billetes contaminados con Blastocystis y Endolimax nana (6). En hortalizas, específicamente en lechugas, se ha conseguido hasta $71 \%$ de contaminación con una diversidad de 11 taxones, siendo nuevamente Blastocystis y E. nana los más comúnmente encontrados (7). Por lo tanto, no es de extrañar que objetos como los pasamanos de los autobuses también están contaminados con diversidad de enteroparásitos, lo que en Venezuela no ha sido estudiado (1-7).

El objetivo de este trabajo es determinar la presencia de parásitos intestinales, como contaminantes de los pasamanos de autobuses que transitan en las distintas zonas de la ciudad de Barquisimeto, discriminando los diferentes taxones encontrados y categorizando la frecuencia de cada especie.

\section{Metodología}

El actual estudio es de tipo descriptivo, transversal, con muestra no probabilística, accidental, con un enfoque de análisis cuantitativo. Se realizó entre junio y julio del 2019 en la ciudad de Barquisimeto, municipio Iribarren (LN 10 $03^{\prime} 55^{\prime \prime}$ - LO 69 $18^{\prime} 53^{\prime \prime}$ ), estado Lara, Venezuela (Figura 1). Esta ciudad se encuentra a una altitud de 520 metros sobre el nivel del mar, con una temperatura media anual de $24,5^{\circ} \mathrm{C}$, precipitación media anual de $624 \mathrm{~mm}$ y clasificación climática de Semiárido Cálido (8).

Las empresas transportadoras aprobarony condicionaron la potestad de cada conductor de colaborar, tal que todos los seleccionados dieron el consentimiento informado. Se tomaron muestras de 100 autobuses pertenecientes a las distintas rutas que circulaban en la ciudad de Barquisimeto. Por normativa legal y de seguridad, todas las rutas tienen que pasar por el Hospital Central Antonio María Pineda de Barquisimeto (Figura 1). Este fue el lugar seleccionado para obtener las muestras. Las principales rutas son las que se dirigen desde este centro hacia el Norte, Sur, Este y Oeste de Barquisimeto, por lo que se seleccionaron 25 de cada región (la cuarta parte cada una). 
Figura 1. Ubicación de la zona de estudio. Venezuela, estado Lara, Barquisimeto. En el círculo rojo central se indica el punto de convergencia desde donde salen o llegan todas las rutas (Hospital Central).

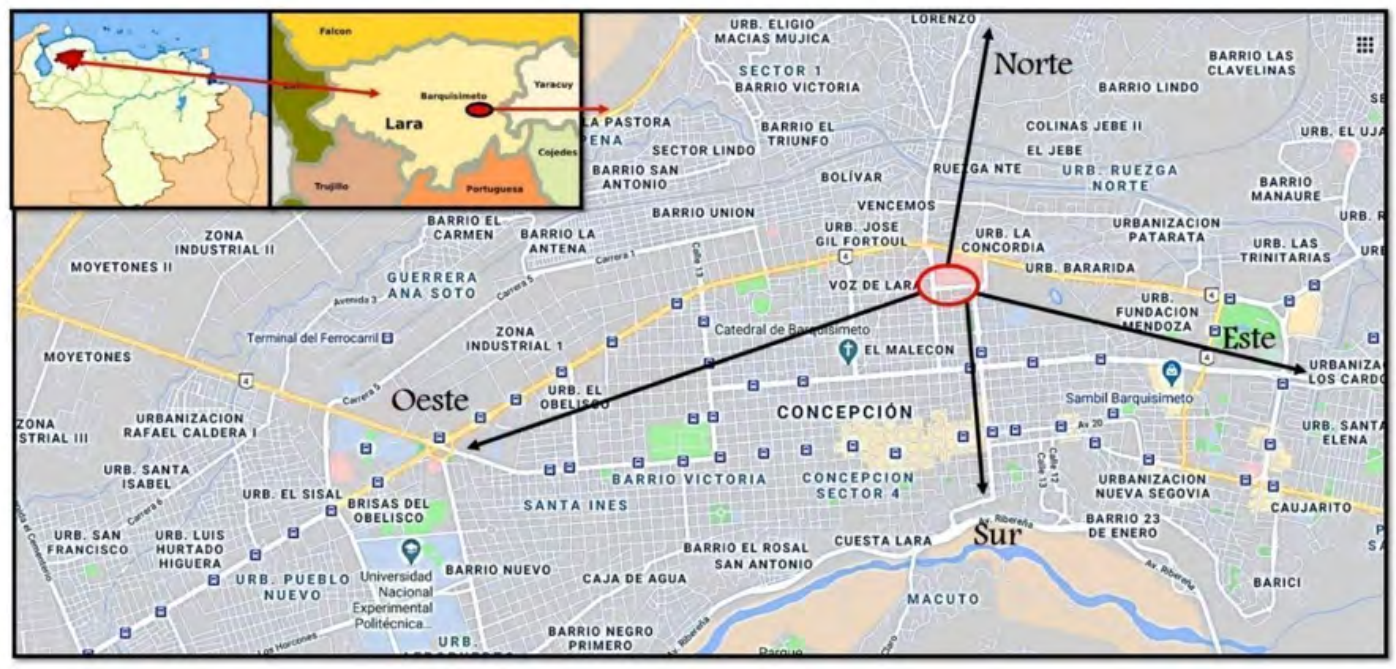

Fuente: elaborada por los autores

En América Latina, por no existir ningún antecedente de muestras de enteroparásitos que fuesen tomadas directamente en autobuses, se tuvo que estandarizar la técnica en el laboratorio en los meses previos a la toma definitiva de las muestras. Se seleccionó el horario de 11:00 a.m. a 1:00 p.m. para conseguir las muestras ya que a primeras horas de la mañana los pasamanos estaban más limpios y al final del día aumentaba la positividad. Se tomó el mediodía como el período más representativo del día. Las muestras (una por cada vehículo) se obtenían de los pasamanos de acero que utilizan los pasajeros para sujetarse. Para esto se tomó un palillo de madera de $153 \mathrm{~mm}$ de largo, con una de sus puntas cubiertas de algodón estéril (hisopo), que era humedecida en solución salina isotónica (SSI) estéril al $0.85 \%$. Esta punta húmeda se frotaba o arrastraba con movimiento rotatorio sobre la superficie del pasamanos durante unos 30 segundos, luego se introducía en el respectivo tubo de ensayo $(16 \times 150 \mathrm{~mm})$ limpio, de tapa de baquelita (rosca), que contenía $10 \mathrm{ml}$ de SSI estéril. Se agitaba el hisopo dentro de la SSI, se sacaba el hisopo del tubo de ensayo y se repetía el procedimiento de frotar sobre otro lugar del pasamanos dos veces más, para finalmente colocar todo el hisopo dentro del tubo de ensayo. Se tapaba, rotulaba y se trasladaba en una cava refrigerada hasta el Laboratorio de Parasitología Médica de la Universidad Centroccidental Lisandro Alvarado (UCLA), Barquisimeto para su análisis en un tiempo menor a las 24 horas (4).

En el laboratorio se abrían los tubos, se sacudía el hisopo dentro de la SSI (para desprender las formas parasitarias residuales del algodón) y luego se sacaba el hisopo. Inmediatamente se calibraron, taparon y se centrifugaron los tubos a $3,000 \mathrm{rpm}$ durante 10 minutos. Seguidamente se descarta el sobrenadante y el sedimento que quedaba se resuspendió (golpes suaves en la palma de la mano) para luego colocar una gota de este sedimento en una lámina portaobjeto, que luego se protegía con una laminilla cubreobjetos de $22 \times 22 \mathrm{~mm}$. Se observa en microscopio óptico (AxioLab, Carl Zeiss) con aumento de 100X y luego con 400X, para apreciar los detalles de los protozoarios observados (Figura 2).

Figura 2. Técnica para recolección de enteroparásitos que contaminan los tubos (pasamanos) de autobuses de Barquisimeto.

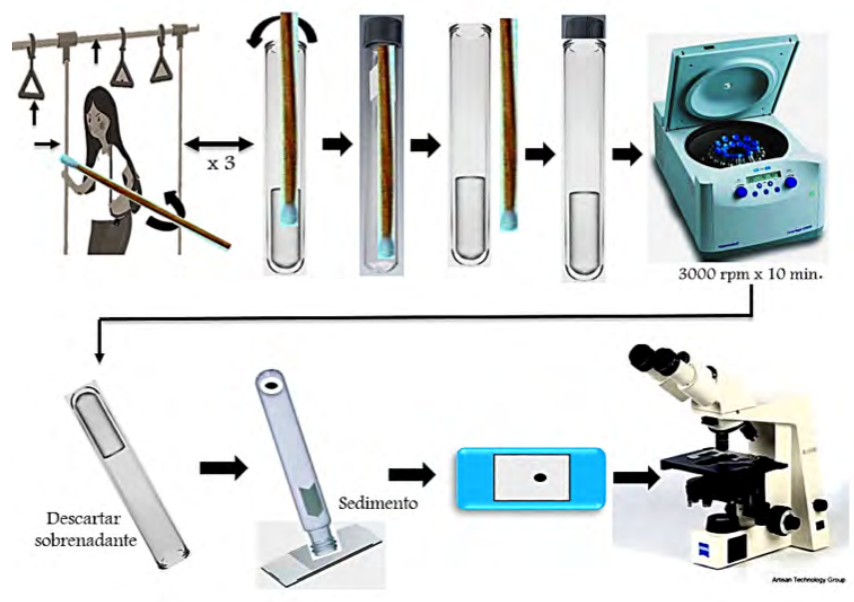

Fuente: elaborada por los autores 
En las muestras positivas se montaba nuevamente el sedimento, pero usando colorante de Lugol para observar mejor las características internas de los parásitos. Las muestras de los autobuses que no presentaron enteroparásitos se identificaron como negativas o no contaminadas, mientras que, si presentaba por lo menos un taxón, la muestra se identificaban como positiva o contaminada. Los que presentaban una sola especie contaminando se identificaban como monocontaminados y los que presentaron dos o más especies simultáneamente, se identificaron como policontaminados.

Se utilizó una base de datos en Excel 2016 expresada en frecuencias absolutas y se calcularon sus porcentajes. La significancia de la relación entre la ruta que recorrían los autobuses y la presencia de parásitos se hizo mediante la prueba de Chi $(\chi 2)$ cuadrado.

\section{Resultados}

Se detectó que el $16 \%$ de los autobuses estudiados con este método estaban contaminados con uno o dos parásitos. $13 \%$ de las muestras de los ómnibus analizados presentaban mono contaminación mientras que un 3\% de los analizados estaban poli contaminados. No hubo correspondencia estadísticamente significativa entre la ruta urbana que recorrían los autobuses y la presencia de algún parásito.

\section{Discusión}

La frecuencia de contaminación enteroparasitaria en autobuses (16\%) los coloca por debajo del riesgo que existe en el estado Lara por contaminación para otros fómites estudiados, tales como los intercomunicadores de los edificios $(65 \%)$, billetes que circulan en esta región $(29 \%)$ o contaminación en lechugas que se expenden en mercados de Barquisimeto, $43 \%$ (4-7).

La diversidad de parásitos encontrados fue escasa (sólo dos taxones) Blastocystis sp (14\% de las unidades de transporte estudiadas) y Endolimax nana (5\%); una alta dupla de entero protozoarios que también se ha señalado en trabajos internacionales en poblaciones de Costa Rica 24\% Blastocystis y $8 \%$ En (2), de Cuba 25\%-5\% (Blastocystis-En) y $87 \%-72 \%$ (Blastocystis-En) $(3,9)$, México 30\% Blastocystis y 29\% En (1), Colombia 58\% Blastocystis y Venezuela 49\%-15\% (Blastocystis-En) (10-15).
Estos dos taxones son los más frecuentemente reportados en fómites de Venezuela, por ejemplo, en intercomunicadores de Barquisimeto (49\% Blastocystis, $36 \% E n)$ y en billetes que circulan en el estado Falcón, donde se presentan hasta con un $47 \%$ Blastocystis y $17 \%$ En, respectivamente (11). Esta dupla infecciosa también es frecuente en estudios de habitantes del estado Lara, con prevalencias de Blastocystis en zonas rurales y urbanas que oscilan entre un $27 \%$ a $71 \%$ (5).

La alta frecuencia de Blastocystis es importante desde el punto de vista clínico, ya que en el hombre puede estar asociada a alternancia de diarrea, tenesmo, náuseas, baja de peso, prurito anal, malestar general, vómito, dolor abdominal, flatulencias, constipación, fiebre, anorexia, pérdida de sangre en las evacuaciones, e incluso, se asocia con síndrome de intestino irritable. Su presencia también se asocia a otros parásitos que pueden ejercer una acción sinérgica patogénica en perjuicio del portador $(4,7,10,11,15,16)$.

Blastocystis sp es un parásito con una amplia capacidad para adaptarse y fijarse a cantidad de fómites, tanto que ha sido descrito contaminando uñas de pacientes $(42 \%$ del total de analizados), agua de panela (48\%), agua del grifo $(39 \%)$, juguetes $(30 \%)$, cáscaras de huevos $(27 \%)$, biberones (19\%) y verduras (del 25\% al 65\%). También se ha descrito contaminando frutas, pisos de madera, pisos de tierra y baldosas, plasticidad adaptativa que podría explicar su alta prevalencia $(4,10)$.

A pesar de que los valores de Blastocystis que se reportan en autobuses son más bajos que los reportados en otros lugares u objetos, esta frecuencia debería ser aún mayor, ya que, al procesar las muestras, estas se centrifugan y está referido que Blastocystis se desfigura o destruye con la centrifugación o se agrupa en la fase de anillos de residuos, lo que dificulta su diagnóstico $(4,9,10)$.

Un elemento que potencia la supervivencia de los enteroprotozoarios sobre los tubos de los autobuses es que estos están hechos generalmente de acero inoxidable, lo que ha demostrado ser un buen material para que microorganismos como el Cryptosporidium spp y quistes de Giardia intestinalis. Esta superficie es más habitable que otras texturas tales como fórmica, cerámica, pieles y tela, ya que el acero tiene menor tasa de extinción que el resto de las superficies citadas de elevada porosidad $(6,11,13)$.

Los enteroparásitos en áreas de mayor porosidad pueden estar expuestos a un aumento del estrés osmótico. No obstante, en el caso de los billetes que circulan 
en Venezuela, que son fabricados a base de fibras de algodón y lino, y que presentan una zona rugosa y porosa que permite que quistes/ooquistes y huevos de enteroparásitos se peguen con mayor facilidad $(6,11,13)$. En muestras tomadas en Colombia se apreció una mayor presencia de Blastocystis en superficies de pisos de madera y tierra, que sobre pisos de cerámica y cemento (10).

Todos los artículos citados, confirman que lavarse las manos antes de preparar los alimentos, comer o luego de ir al baño es la medida clave para controlar la transmisión de enteroparásitos por contaminación, ya que la falta de limpieza está íntimamente relacionada con la aparición de síntomas como el vómito o la diarrea $\mathrm{y}$, en el caso del presente trabajo, las manos sucias de un solo usuario podría contaminar los tubos sujetadores de toda la unidad y por consiguiente extender este problema a las siguientes personas que utilicen el transporte $(1,4)$.

La costumbre de lavado es, lamentablemente, escasa en Latinoamérica, generalmente por elementos culturales y por la falta de disposición constante de agua potable. En Perú se ha señalado que solo el 11\% de las personas se lavan las manos luego de defecar, y el uso de jabón es menos frecuente aún. El jabón permite destruir la mayoría de los agentes infectantes (virus, bacterias, parásitos) y los que son resistentes, simplemente son desplazados o arrastrados por el agua jabonosa (13-14).

\section{Conclusiones}

La contaminación del $16 \%$ de las muestras de los autobuses analizados con una diversidad de dos taxones de enteroparásitos indica que existe un riesgo real de transmisión de enfermedades en estos vehículos de tránsito público $\mathrm{y}$, por consiguiente, que es necesaria la descontaminación constante de estas unidades de transporte con sustancias químicas microbicidas para neutralizar la transmisión de estos protozoarios y de otros agentes infecciosos que pudieran estar coligados, tales como hongos, bacterias y virus (como el COVID 19). También es necesario incrementar la educación sanitaria de todos los usuarios, porque la salud de uno tiene importantes consecuencias sobre la salud de quienes lo rodean.

Consideraciones Éticas. Se siguieron las normas de la Declaración de Helsinki, renovadas en la Asamblea General de la Asociación Médica Mundial en la ciudad de Fortaleza - Brasil, 2013. Se obtuvo el consentimiento informado de cada conductor.

Agradecimientos. A la Licenciada Elsys Cárdenas por su apoyo.
Conflicto de Intereses. Los autores expresan no tener conflicto de intereses adecuados a este artículo.

Fuentes de financiación. La investigación fue autofinanciada.

\section{Referencias}

1. Flores U., Franco L., Orozco N., Trejo I., Tlazola R., Barragán N. et al. Enfermedades parasitarias dependientes de los estilos de vida. Journal of Negative \& no Positive Results. 2018; 3(6): 398-411. doi: 10.19230/jonnpr.2409.

2. Solano M., Montero A., León D., Santamaría C., Mora A., Reyes L. Prevalencia de parasitosis en niños de 1 a 7 años en condición de vulnerabilidad en la Región Central Sur de Costa Rica. Acta Médica Costarricense [Internet]. 2018; 60(2): 19-29.

Disponible en: https://www.scielo.sa.cr/scielo. php?pid=S0001-60022018000200019\&script $=$ sci abstract\&tlng=es

3. Aleaga Y., Domenech I., González Z., Martínez A., Martínez IF. Blastocystis spp. y otros enteropatógenos en pacientes pediátricos atendidos en el Hospital "Juan Manuel Márquez". Rev Panorama Cuba y Salud [Internet]. 2019; 14(2):29-33. Disponible en: http://www.revpanorama.sld.cu/index.php/rpan/ article/view/.

4. Traviezo L., Machuca B., LópezA., JiménezA., Lozada W., Lee Y. et al. Contaminación enteroparasitaria de intercomunicadores en edificios de Barquisimeto y Cabudare, Venezuela. NOVA [Internet]. 2019; 17 (32): $65-74 ; 14(2): 29-33$.

Disponible en: http://www.scielo.org.co/ scielo.php? script $=$ sci abstract\&pid $=\mathrm{S} 1794$ 24702019000200065\&lng=en\&nrm=iso\&tlng=es

5. Galíndez A., Cárdenas E., Traviezo L. Blastocystis $\mathrm{sp}$, un protozoario endémico en el estado Lara, Venezuela. Bol Méd Post [Internet]. 2016; 32(1):7072. Disponible en: https://www.researchgate. net/publication/343190241_Blastocystis_sp_ un_protozoario_endemico_en_el_estado_Lara Venezuela

6. Traviezo L., Cárdenas E., Jaspe G., Jaspe M., Heredia $\mathrm{K}$, Morantes L. et al. Enteroparásitos en papel moneda que circula en el eje Barquisimeto-Cabudare del estado Lara, Venezuela. Rev Vzlana Salud Pub [Internet]. 2016; 4(2):23-26. Disponible en: https:// dialnet.unirioja.es/servlet/articulo? codigo $=6570440$

7. Traviezo L., Salas A., Lozada C., Cárdenas E., Martín J., Agobian G. Detección de enteroparásitos en lechugas que se comercializan en el estado Lara, Venezuela. Rev Méd-Cient "Luz Vida" [Internet]. 2013; 4(1):7-11. Disponible en: https://dialnet. unirioja.es/servlet/articulo?codigo $=4699480$ 
8. Ministerio del Ambiente. Atlas del estado Lara. 1998 [Internet]. Servicio Autónomo de Geografía y Cartografía Nacional. Barquisimeto, Venezuela. Disponible en: www.laraenred.com $>$ atlas 2017

9. Mendoza D., Núñez F., Escobedo A., Pelayo L., Fernández M., Torres D. et al. Utilidad de dos métodos coproparasitológicos y su empleo en un ensayo terapéutico antigiardiásico. Rev Cubana Med Trop [Internet]. 2003; 55(3): 174-8. Disponible en: http://scielo.sld.cu/scielo.php?script=sci arttext\&pid=S0375-07602003000300007

10. Londoño-Franco A., Loaiza J., Lora F. y Gómez J. Frecuencia y fuentes de Blastocystis sp. en niños de 0 a 5 años de edad atendidos en hogares infantiles públicos de la zona urbana de Calarcá, Colombia. Biomédica. 2014; 34: 218-227. doi: http://dx.doi. org/10.7705/biomedica.v34i2.2124.

11. Morales P, Cazorla D, Antequera I, Navas P, Acosta M. Contaminación de billetes con enteroparásitos en Coro, estado Falcón, Venezuela. Bol Mal Salud Amb[Internet]. 2014;54(1): 38-46. Disponibleen:http://ve.scielo.org/scielo. php?script=sci_arttext\&pid=S1690-46482014000100005.
12. Traviezo L., Alejos M., Antonini M., Escobar C., Pérez M., Pérez F. et al. Contaminación enteroparasitaria de moscas capturadas en el municipio Palavecino, estado Lara, Venezuela. Rev Méd Urug. 2018; 34(4): 215219. doi: http://dx.doi.org/10.29193/rmu.34.4.4

13. Alum A., Absar I., Joseph H., Rubino J., Ijaz K. Impact of Environmental Conditions on the Survival of Cryptosporidium and Giardia on Environmental Surfaces. Interdiscip Perspect Infect Dis. 2014; 2014 (210385):1-7. Doi: http://dx.doi. org/10.1155/2014/210385

14. Vidal-Anzardo M., Yagui M., Beltrán M. Parasitosis intestinal: Helmintos. Prevalencia y análisis de la tendencia de los años 2010 a 2017 en el Perú. An Fac Med. 2020; 81(1): 26-32. doi: https://doi. org/10.15381/anales.v81i1.17784

15. Devera R., Soares A., Rayarán D., Amaya I., Blanco Y. Enteroparasitosis en escolares: importancia de los parásitos asociados. Rev Venezolana Salud Púb [Internet]. 2020; 8 (1) 49-64. Disponible en: https:// dialnet.unirioja.es/servlet/articulo? codigo $=7509598$ 